\title{
INFLUÊNCIA DA PRESENÇA DE ÓLEO DE LAMINAÇÃO NO AQUECIMENTO DE TIRAS DE AÇO LAMINADAS A FRIO*
}

\author{
Luana Araújo Batista ${ }^{\top}$ \\ Cláudio Moreira de Alcântara ${ }^{2}$ \\ Wilian da Silva Labiapari ${ }^{3}$
}

\section{Resumo}

Na produção de tiras de aço laminadas a frio, o material é encaminhado para linhas de recozimento e decapagem de bobinas. Geralmente, essas linhas de produção possuem sistemas de lavagem para remoção do óleo de laminação e outras impurezas da superfície da tira. Porém, em algumas situações de processo ou por limitações técnicas, o óleo da superfície não é totalmente eliminado. Neste trabalho foi avaliada a influência do óleo de laminação na superfície do aço inoxidável AISI 430 durante o recozimento após laminação a frio. A motivação deste estudo surgiu da necessidade de compreender o fato das amostras oleadas deste aço apresentarem martensita após o recozimento, o que não ocorre para amostras recozidas sem óleo. Para os ensaios foram utilizados dois fornos mufla e diferentes concentrações de oxigênio na atmosfera, sendo utilizados termopares acoplados em todas as amostras. Foi comprovado que a presença de óleo na superfície da tira acelera a taxa de aquecimento e aumenta a temperatura final da tira em aproximadamente $100^{\circ} \mathrm{C}$ quando comparada às amostras não oleadas para o ciclo estudado.

Palavras-chave: Óleo de laminação; Aquecimento de tira; Termopar; Formação de martensita.

\section{INFLUENCE OF COLD ROLLING OIL ON STRIP AT HEATING TEMPERATURE DURING ANNEALING PROCESS}

\section{Abstract}

In the production of cold-rolled steel sheet, usually the material has a subsequent process of annealing and pickling. Generally, these production lines have washing system to remove the cold rollig oil and other impurities from the surface of the strip. However, sometimes the oil is not totally eliminated. The aim of this work was to evaluate the influence of cold rollig rolling on the surface of stainless steel AISI 430 during annealing process. It was motivate due to the fact that oiled steel samples has martensite after annealing process, while annealed samples without oil did not present martensite. It was used two laboratory furnaces with different oxygen contents and thermocouple engaged in all samples. It was proved that the presence of oil on the surface of the strip changes the heating rate and the annealed temperature is $100^{\circ} \mathrm{C}$ higher for the oiled samples than not oiled ones.

Keywords: Rolling oil; Strip heating; Thermocouple; Martensite formation.

Graduanda em Engenharia Metalúrgica no Centro Universitário do Leste de Minas GeraisUnileste, Associada ABM Júnior, Coronel Fabriciano, Minas Gerais, Brasil.

2 Tecnólogo em Soldagem, Técnico de Pesquisa, Centro de Pesquisas, Aperam South America, Associado ABM, Timóteo, MG, Brasil.

3 Engenheiro Mecânico, Doutorando, Pesquisador, Centro de Pesquisas, Aperam South America, Associado ABM, Timóteo, MG, Brasil. 


\section{INTRODUÇÃO}

Durante o processo de laminação a frio de aços, o material é oleado com o principal objetivo de reduzir o atrito entre o cilindro de trabalho e a tira de aço, facilitando a redução da espessura. Na fabricação de aços inoxidáveis, após a laminação a frio, o material é encaminhado para linhas de recozimento e decapagem final de bobinas. Geralmente, essas linhas possuem sistemas de lavagem para remoção do óleo de laminação e outras impurezas da superfície da chapa. No entanto, seja pela própria condição de processo ou por problemas técnicos, a limpeza da tira pode não ser executada, o que faz com que o material seja recozido com óleo.

Em estudo realizado paralelamente a este pelos autores, para verificar a influência do óleo de laminação na ocorrência de defeitos superficiais no aço inoxidável AISI 430 , ensaios de recozimento de amostras laminadas a frio foram executados. Foram recozidas amostras com a superfície oleada e sem óleo. Em seguida foi avaliada a microestrutura das amostras sendo constatada a presença de martensita nas amostras que foram recozidas oleadas. Por outro lado, as amostras recozidas sem a presença de óleo na superfície apresentaram estrutura ferrítica, como esperado. Ferreira [1] evidencia em seu estudo que, após o recozimento final, a microestrutura típica do AISI 430 é uma matriz ferrítica com distribuição homogênea de carbonetos finos de cromo.

Porém, segundo Silva [2], o aço AISI 430 pode apresentar de 30-50\% de austenita quando aquecido acima de $800^{\circ} \mathrm{C}$. Portanto durante o resfriamento, a austenita se transformará em martensita, resultando em uma estrutura final composta de ferrita e martensita.

Houve então a necessidade de compreensão do mecanismo que diferenciava as estruturas entre as amostras com e sem óleo na superfície. No referido ensaio, coletou-se os dados da curva de aquecimento do material com a superfície sem óleo, auxiliado por um termopar, e considerou-se que a curva de aquecimento seria a mesma para as amostras oleadas. Como as amostras tinham as mesmas dimensões e permaneceriam no forno durante o mesmo tempo havia a expectativa de que não haveria alterações na temperatura de amostra.

Com a transformação de fase do aço surgiu a suspeita de que o óleo na superfície da tira poderia alterar o aquecimento do aço, e consequentemente, contribuir para a formação de martensita. Dessa forma, o presente trabalho tem como objetivo avaliar a influência da presença de óleo no aquecimento da tira durante o recozimento final do aço inoxidável AISI 430 laminado a frio. Também foi avaliada a influência do teor de oxigênio presente na atmosfera do forno no aquecimento deste aço.

\section{MATERIAIS E MÉTODOS}

Utilizaram-se amostras do aço AISI 430 encruado, retiradas após a laminação a frio da planta industrial da Aperam South America, em Timóteo. Foram cortadas na dimensão de $1,50 \times 50 \times 100 \mathrm{~mm}$ e desengraxadas. Parte das amostras foram oleadas com óleo de laminação do tipo Dairoll NS-12/30HS [3], composto por hidrocarboneto derivado do petróleo, éster e aditivo antioxidante, e outra parte não, sendo todas enviadas para recozimento.

Através do software Thermo-Calc, que se baseia na composição química da amostra e em equações termodinâmicas, pode-se definir o diagrama de fase para o aço de interesse. O Thermo-Calc permite a entrada dos teores dos principais elementos de liga do aço e a faixa de temperatura de interesse. Pode-se determinar a variável 
desejada para cada um dos eixos do diagrama, como temperatura, porcentagem de uma determinada fase, teor de um elemento químico, etc. As informações de entrada do software e o diagrama podem ser observados abaixo.

Tabela 1. Valores de entrada no Thermo-Calc para o aço 430A

\begin{tabular}{cccccc} 
C [\%] & Mn [\%] & Si [\%] & Cr [\%] & Ni [\%] & N2 [ppm] \\
\hline & & & & & \\
0,0452 & 0,2126 & 0,2865 & 16,1659 & 0,1363 & 712 \\
\hline
\end{tabular}

A temperatura de tira objetivada foi baseada no diagrama gerado pelo Thermo Calc e o tempo de recozimento foi fixado em 82 segundos, considerando-se o tempo total de aquecimento da tira em laboratório. A temperatura de tira de todas as amostras foi controlada por termopar do tipo $\mathrm{K}$, acoplado nas amostras, e registrador de temperatura.

Para avaliar a influência do teor de oxigênio no aquecimento foram utilizados dois fornos do tipo mufla. O primeiro com teor de oxigênio de aproximadamente $9 \%$ e o segundo aproximadamente $21 \%$. A temperatura dos fornos foi fixada em $1030^{\circ} \mathrm{C}$ e o resfriamento das amostras foi ao ar.

\section{RESULTADOS E DISCUSSÃO}

Na Figura 1 se encontra o diagrama de fases obtido pelo Thermo Calc do aço em estudo em função do teor de carbono. Observa-se que a amostra começa a austenitizar em temperaturas superiores a $843^{\circ} \mathrm{C}$. Foi objetivada então uma temperatura final de recozimento acima desta temperatura.

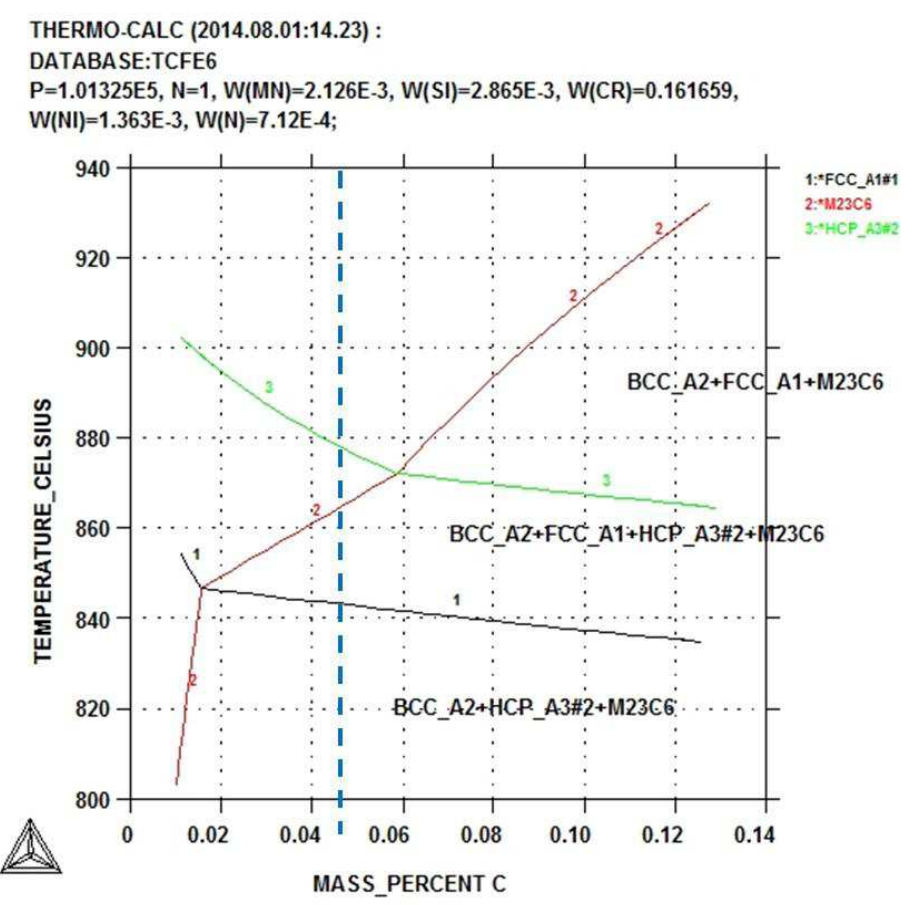

Figura 1. Formação de fases em função do teor de carbono e da temperatura para a amostra de AISI 430. A linha tracejada azul corresponde à composição da amostra.

Com a utilização de termopar em todas as amostras, verificou-se que para uma mesma temperatura de forno $\left(1030^{\circ} \mathrm{C}\right)$ e dimensões do aço AISI 430 , o material 
oleado apresentou maior taxa de aquecimento comparado ao não oleado. Também foi observada a maior temperatura final das amostras oleadas, sendo essas constatações independentes do teor de oxigênio na atmosfera do forno, Figura 2.

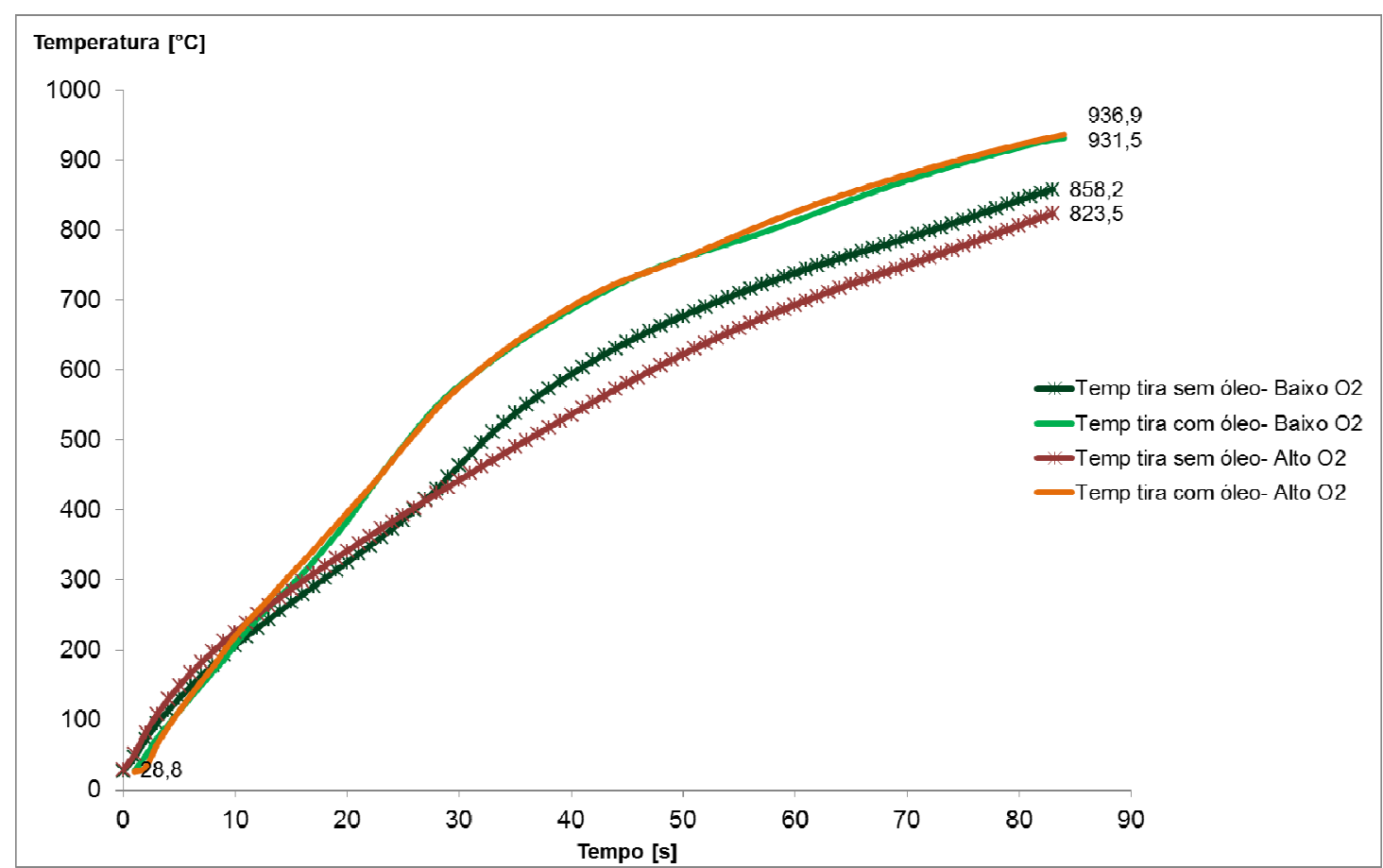

Figura 2. Curvas de aquecimento de amostras do aço AISI 430 com e sem óleo na superfície, recozidas em atmosfera com baixo ( $9 \%$ ) e alto $(21 \%)$ teor de oxigênio, na mesma temperatura de forno $\left(1030^{\circ} \mathrm{C}\right)$.

No início do aquecimento as amostras com óleo apresentaram menor aquecimento em relação às amostras sem óleo, provavelmente devido ao fato do calor ser absorvido pelo óleo para aquecimento e combustão do mesmo. Após alguns segundos o óleo da superfície entra em combustão e a temperatura da tira é acrescida, independente do teor de oxigênio do forno, e passam a ter maior temperatura de tira. A maior diferença térmica entre as amostras com e sem óleo foi na condição de maior teor de oxigênio, com variação de $113,4^{\circ} \mathrm{C}$.

Pela análise da proporção de austenita em função da temperatura para esse aço, Figura 3, pode-se observar que as amostras oleadas atingiram as temperaturas mais altas (Figura 2), sendo o suficiente para que houvesse a austenitização de cerca de $60 \%$ do material. 
THERMO-CALC (2014.05.30:16.35) :

DATABASE:TCFE 6

$\mathrm{P}=1.01325 \mathrm{E} 5, \mathrm{~N}=1, \mathrm{~W}(\mathrm{C})=4.67 \mathrm{E}-4, \mathrm{~W}(\mathrm{MN})=2.969 \mathrm{E}-3, \mathrm{~W}(\mathrm{~S} \mathrm{I})=2.867 \mathrm{E}-3$,

$W(C R)=0.161695, W(N)=5.09 E-4, W(N I)=3.096 E-3$;

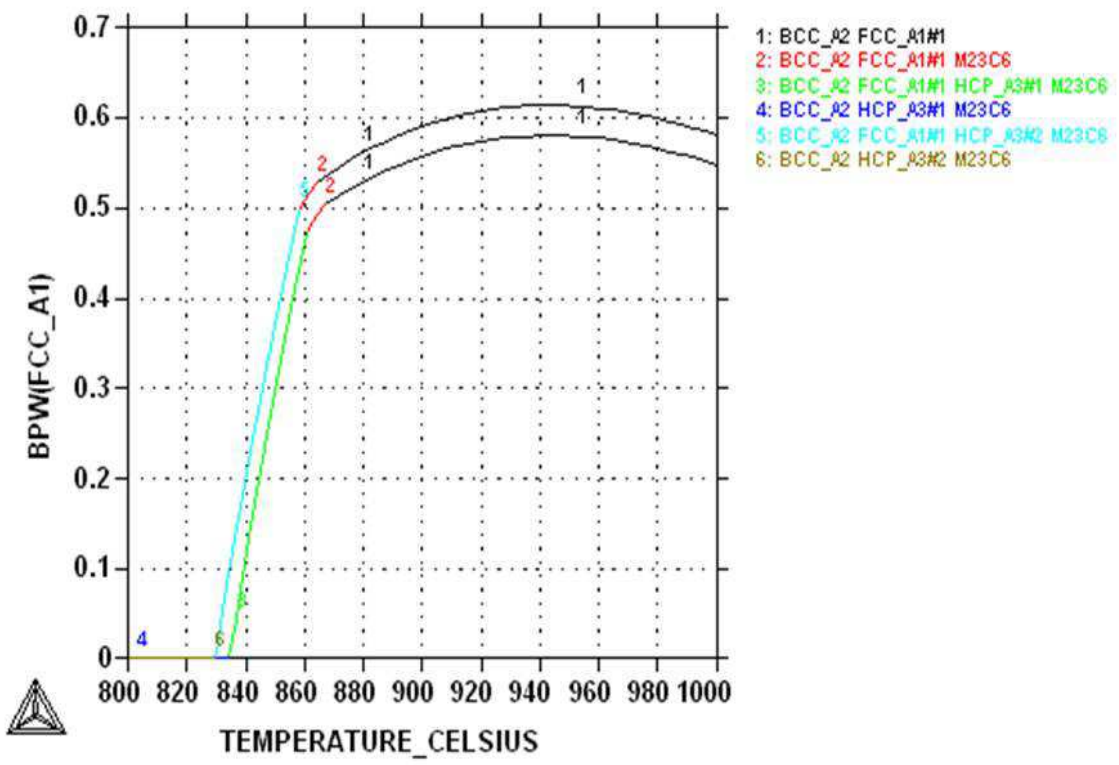

Figura 3. Fração de austenita em função da temperatura para o aço AISI 430.

Verificou-se que as amostras de AISI 430 recozidas com a superfície oleada, tanto com baixo quanto com alto teor de oxigênio, apresentaram dureza elevada característica de formação de martensita. A dureza média das referidas amostras foi de 93,8 HB e 90,6 HB, respectivamente, enquanto a dureza padrão deste aço é de 70 a 85 HB. O que foi confirmado pela análise metalográfica. A maior fração de martensita foi observada nas amostras recozidas com menor teor de oxigênio, que tiveram a queima do óleo menos eficiente.

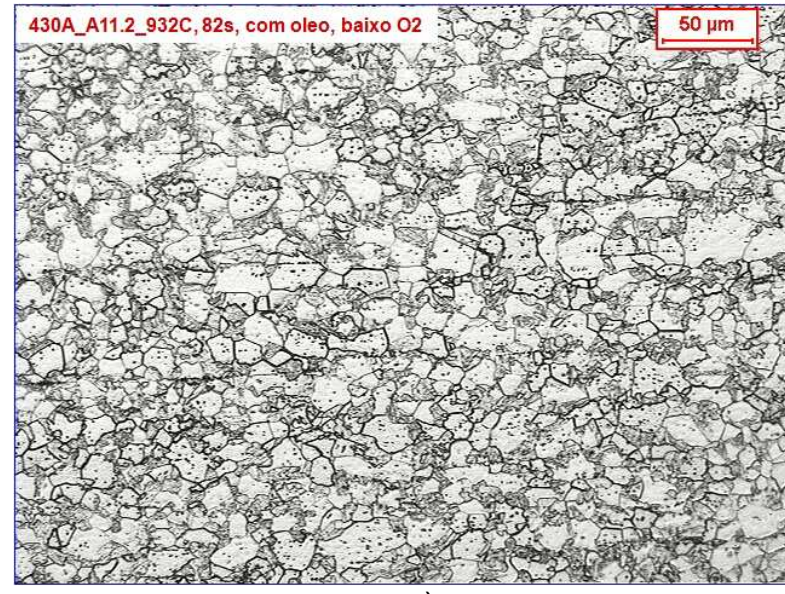

a)

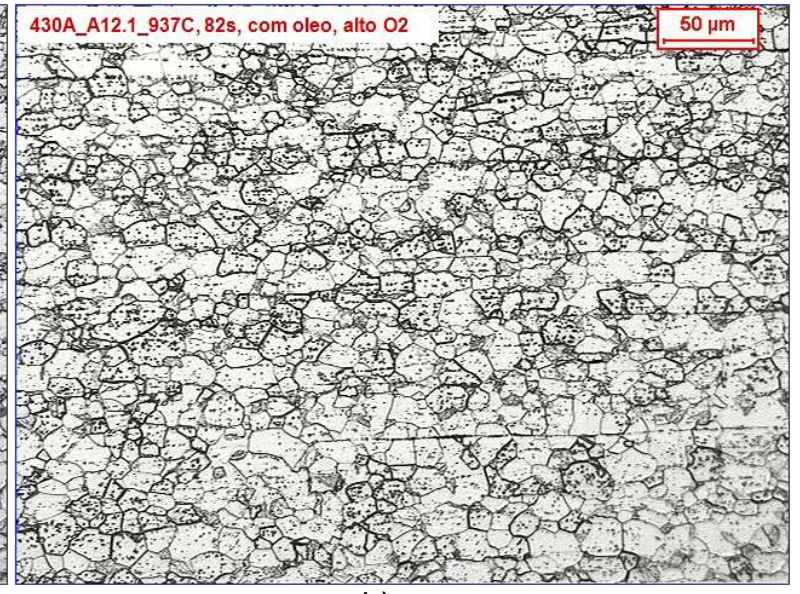

b)

Figura 4. Amostras do aço AISI 430 com formação de martensita após recozimento. (a) recozida com óleo e em baixo O2 ( 9\%) e (b) recozida com óleo e em alto O2 ( 21)

A maior temperatura nas amostras oleadas explica a formação de martensita, não observada nas amostras não oleadas. Esta constatação foi possibilitada pela utilização de termopar em todos os ensaios, o que aumentou a confiabilidade dos resultados. 
Pelos resultados obtidos não se pode concluir o motivo do óleo aquecer a tira, mas acredita-se que seja pela alteração na emissividade do aço. Como pode ser observado na Figura 5, a amostra oleada, após recozimento, apresenta óxidos de coloração diferentes da não oleada. Estima-se que os óxidos formados juntamente com o resíduo carbonoso do óleo tenham maior capacidade de absorção de calor, aumentando a emissividade do aço.

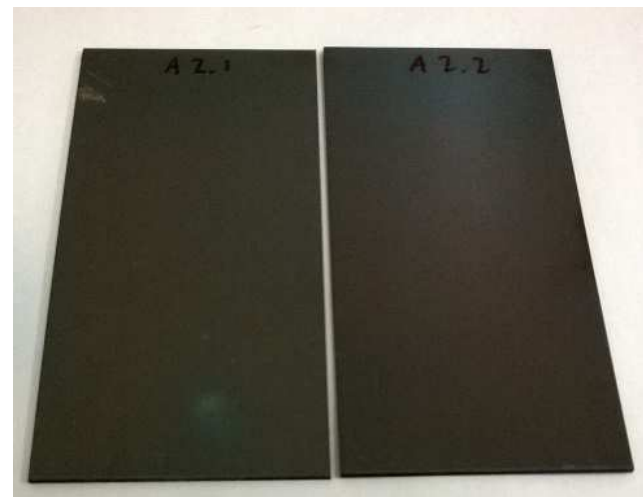

(a)

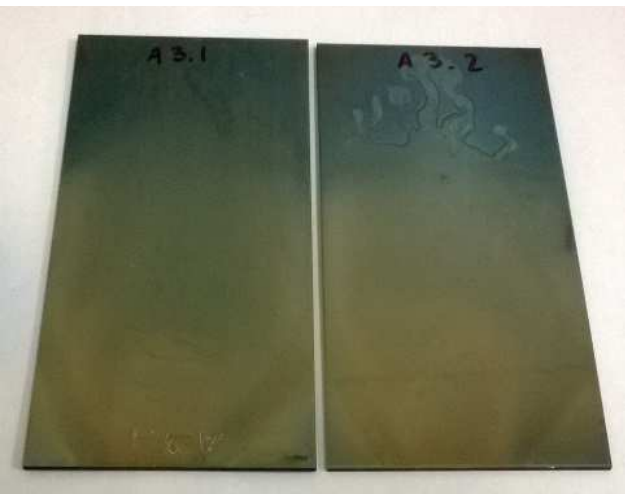

(b)

Figura 5. Superfície das amostras do aço ASI 430 (a) recozido sem óleo e (b) recozido oleado.

\section{CONCLUSÃO}

O óleo de laminação presente na superfície da tira do aço AISI 430 durante o recozimento final altera a taxa de aquecimento do material. Para uma mesma temperatura de forno $\left(1030^{\circ} \mathrm{C}\right)$, amostras com óleo apresentaram maior taxa de aquecimento e temperatura final maior do que amostras sem óleo, com variações térmicas superiores a $100^{\circ} \mathrm{C}$. Esse fato indica que a presença de óleo na superfície da chapa influencia no comportamento térmico do mesmo.

Os resultados deste estudo indicam que o recozimento de tiras do aço inoxidável AISI 430 em uma condição mais oleada pode gerar a formação de martensita devido à elevação da temperatura do aço.

\section{Agradecimentos}

A Aperam South America, unidade de Timóteo em Minas Gerais.

\section{REFERÊNCIAS}

1 Ferreira, J. S. Efeito da fração volumétrica de martensita, formada no resfriamento após recozimento intercrítico, no grau de estriamento, propriedades mecânicas e estampabilidade de um aço tipo AISI 430. Dissertação de mestrado. Belo Horizonte: Universidade Federal de Minas Gerais; 2005.

2 Silva, A. L. da C. Mei, P. R. Aços e ligas especiais. 2o ed. Sumaré: Eletrometal S.A. Metais especiais; 1988.

3 Daido Quimica do Brasil LTDA. Ficha de informações de segurança de produto químico - Dairoll NS-12/30HS. Contagem. Revisão 2012. 